\title{
COMMENTS ON THE BILDERBERG CONTINUUM ATMOSPHERE *
}

\author{
GÜNTHER ELSTE \\ Dept. of Astronomy, The University of Michigan, Ann Arbor, Michigan, U.S.A.
}

(Received 24 October, 1967)

\begin{abstract}
The Bilderberg Continuum Atmosphere fails to reproduce the observed limb-darkening throughout the range of wavelengths $4500 \AA<\lambda<25000 \AA$. The temperature-pressure diagram for the deep layers of this model is a curve which is flatter than the relation predicted from the mixing length theory. A modification of the Bilderberg Continuum Atmosphere that improves representation of the observations and theoretical results is proposed.
\end{abstract}

\section{Introduction}

The Bilderberg Continuum Atmosphere at the depth range of $0.1 \leqslant \tau_{5000} \leqslant 10$ has unfortunately been based on an average over several temperature distributions rather than on an optimum fitting of the observed limb-darkening over a large wavelength range. It is evident in Figure 1 that the adopted procedure leads to an unsatisfactory graduation of the best available measurements of limb-darkening for a range of wavelengths restricted to $4500 \AA<\lambda<25000 \AA$.

\section{Observational Basis}

References to all known measurements of limb-darkening have been appended in a special section of this paper. These have been critically reviewed before the start of the present work. In order to compare observations made at different values of $\mu=\cos \theta$, a set of five limb distances was selected for which all limb-darkening observations were interpolated. It was found practical to interpolate the $\log \left[I_{\lambda}(\mu) / I_{\lambda}(1)\right]$ as a linear function of $\log \mu$. The data from the various observers were then plotted against wavelength. Whenever systematic differences were found, the observing techniques and possible sources of errors have been investigated. If the proper information was missing the observations were rejected. As a result one gains the impression that the extensive and careful photoelectric measurements by PIERCE (1954), obtained with the Snow telescope at Mt. Wilson, can be considered the best after proper correction for scattered light (DAvid and ElSTE, 1962). Up to about $15000 \AA$ Peyturaux's $(1952,1955)$ observations agree with these within $\frac{1}{2}$ of $1 \%$. This is quite good considering the lower spectral purity available, and the fact that nothing is known about the scattered light. Towards longer wavelengths Peyturaux's measurements lie systematically up to $1 \%$ below those of Pierce as well as PIERCE et al. (1950). All three of these observational sets are used in Figure 1.

* The work described here was supported in part by Contract N(onr)-1224(19) with the Office of Naval Research. 


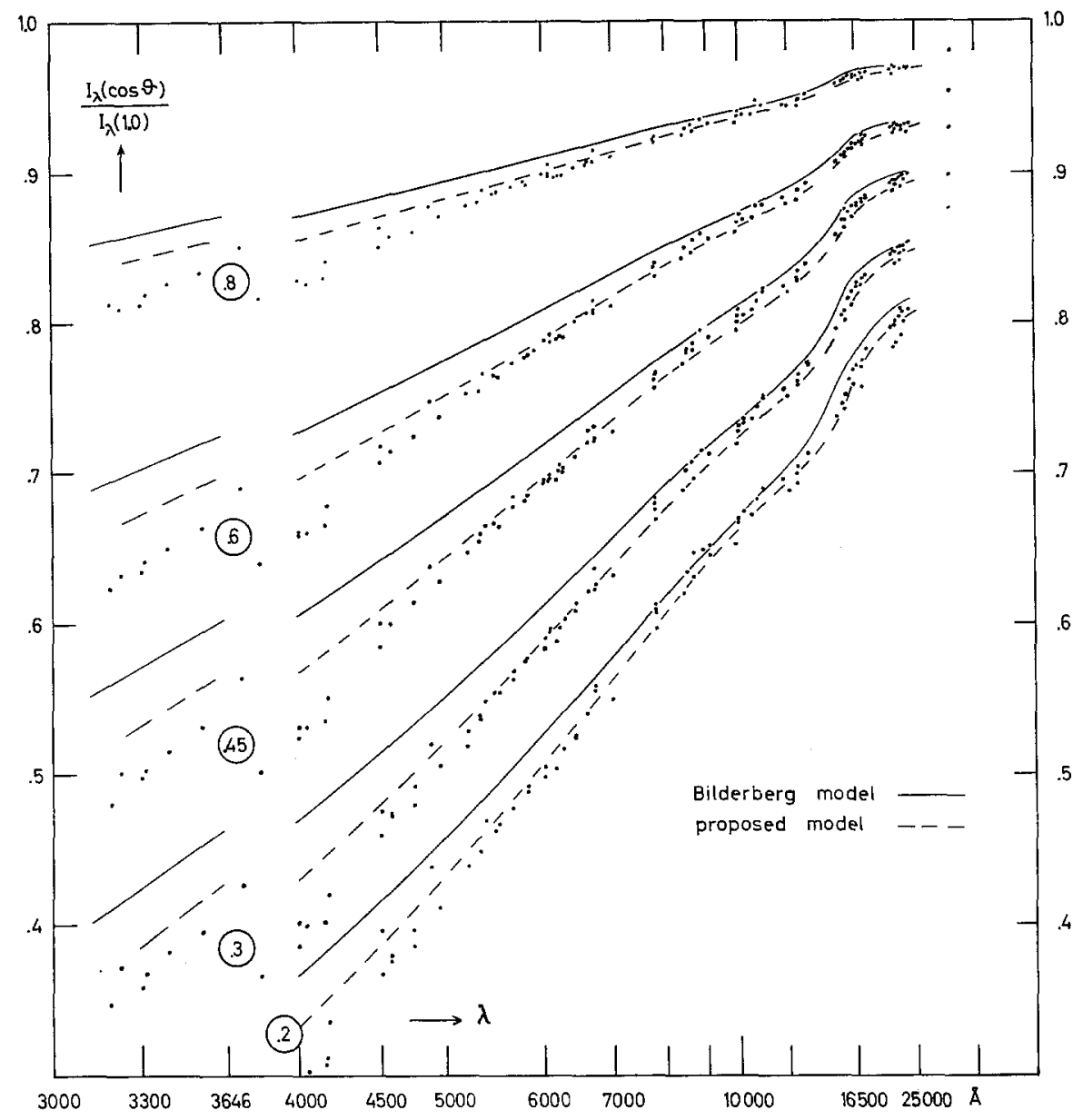

Fig. 1. Comparison between observed and predicted limb-darkening for $3000<\lambda<25000 \AA$. The values of the parameter $\mu=\cos \theta$ are $0.8,0.6,0.45,0.3$, and 0.2 , respectively.

\section{Semi-Empirical Solar Models}

Explaining the observed limb-darkening and energy distribution is not the only condition which we may impose on a model. We know from sufficient observational evidence that the hydrogen convection zone lies below the photosphere. Therefore it is reasonable to require for the deep layers that the model atmosphere should behave in the temperature-pressure diagram as the theory predicts for the transition region between photosphere and convection zone. Mrs. BöHM-VITENSE (1958) has calculated such diagrams with the help of the mixing length theory for stars of different effective temperature and luminosity.

A model constructed on this basis was reported at the meeting of the 'Deutsche Astronomische Gesellschaft' at Weimar in 1960 (ELsTE, 1960). Instead of solving simultaneously for both the temperature model and the wavelength dependence of 
the optical depth $\tau_{\lambda}$ by employing an analytic method, the theoretically computed absorption coefficient was used to calculate the optical-depth scales. Since this procedure requires knowledge of the pressures, they first were determined by the integration of the hydrostatic equation, to be discussed later. The remaining steps follow standard procedures. Starting from the model published by GolDBERG and PIERCE (1959) further improvements were obtained by repeated trials. Herein the contribution curves for the continuum emission, i.e., the integrands of the expressions for the specific intensity, served as indicators for the sensitivity range of the limb-darkening at each wavelength. As can be seen in Figure 2 for a few samples, the shapes of the contribution curves, their positions at the disk center, and their shifts with $\cos \theta$ depend on the wavelength. Thus, by sounding out the atmosphere with probes of different widths this procedure allows to use the whole information content of the measurements with advantage.

For this first model, called No. 9, the energy distribution at the center of the solar disk has been taken from the measurements by LaBs (1957) made at the Pic-du-Midi. MATTIG and SCHRÖTER (1961) have used this model in a successful explanation of the center-to-limb variation of the wings of the Na D-lines. It appears even more impor-

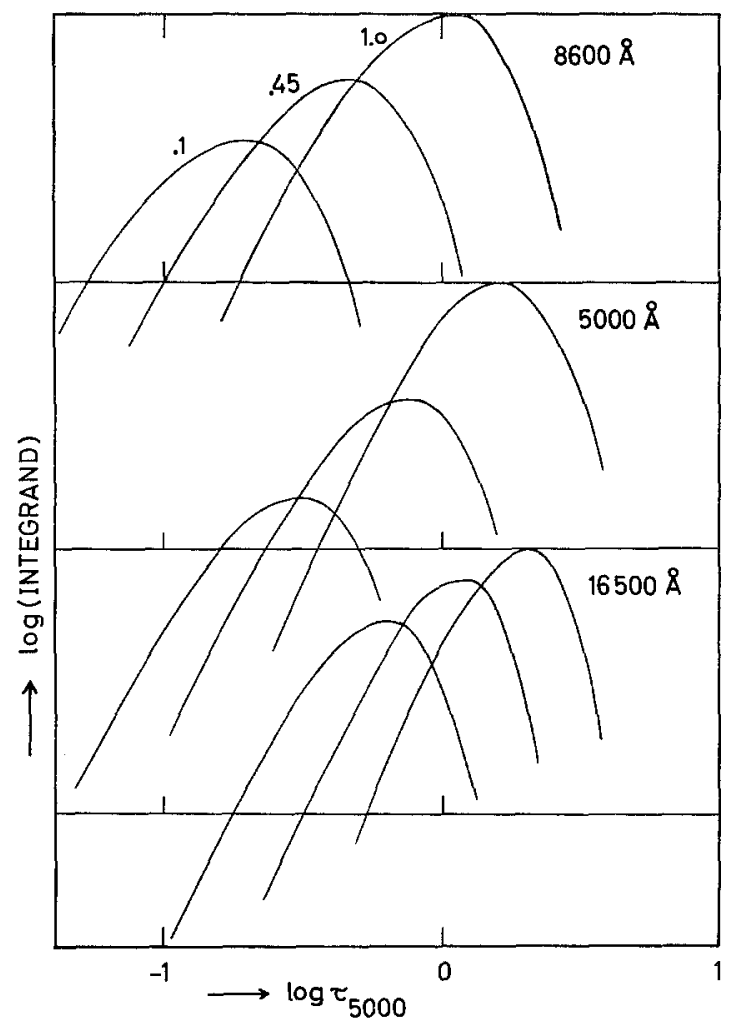

Fig. 2. Center-to-limb variation of the contribution to the continuum emission at the wavelengths 8600,5000 , and $16500 \AA$ displayed as logarithms of the integrands as a function of $\log \tau_{5000}$. The three values of the parameter $\mu=\cos \theta$ are $1.0,0.45$, and 0.1 . 
tant to me, that the center-to-limb variation of the wings of the Balmer lines $\mathrm{H} \alpha-\mathrm{H} \delta$ could be reproduced, as has been shown by DAvID (1961). The high excitation energy of the second quantum state of hydrogen prevents a contribution to the line absorption in the wings of these lines except from very deep layers around $\tau=3$. Moreover, the contribution functions are rather sharp as compared with those for the continuum emission. Therefore these lines offer a possibility for checking the model in the transition region to the hydrogen convection zone, which otherwise is not accessible for continuum observations in the visible.

After completion of the new determination of the energy distribution at the disk center by LABS and NECKEL $(1962,1963,1967)$ a small correction in $\Theta=5040 / \mathrm{T}$ had to be applied, which then led to model 10 (ELSTE, 1967). Actually this difference is too small to affect the line spectrum appreciably. Mugglestone used it for the wings of the Na D-lines, Withbroe (1967) for the profiles of the lines of the CH molecule, WiThBroe (1968) for the center-to-limb variation of the equivalent widths of $\mathrm{C}_{2}, \mathrm{CH}$, $\mathrm{CN}, \mathrm{CO}$, and MgH lines, and ElSTE (1967) for the investigation of the micro- and macroturbulence.

The models so far had been computed for a helium-to-hydrogen ratio of 0.16 , and the abundances of the remaining elements according to GOLDBERG et al. (1960). But since (i) the calculations for the internal structure of the sun favor a lower value for the helium-to-hydrogen ratio of about 0.1 , and (ii) the investigation of the ultraviolet spectrum points towards a temperature stratification of the outer photosphere as given in the Bilderberg Continuum Atmosphere, corresponding changes have been introduced in the model here proposed.

\section{Discussion}

Although not yet ideal the new model represents an improvement with respect to the Bilderberg model in both the limb-darkening and the behaviour in the temperaturepressure diagram (Figure 3) for the transition region between the photosphere and the hydrogen convection zone. The best reference curve for the latter is that obtained by KoHL (1967) for the chemical composition used by VARDYA (1964) with $\mathrm{He} / \mathrm{H}=$ 0.125 . It can be noticed that the Bilderberg model uses too low temperatures in the deepest layers, while the proposed model follows more closely in its depth dependence the curve by Kohl.

For the discussion of the limb-darkening we have plotted in Figure 1 as dots the observed $I_{\lambda}(\mu) / I_{\lambda}(1)$ for certain representative values of $\mu=\cos \theta$ as a function of $1 / \lambda$. The relations predicted by the Bilderberg model and by the proposed model are drawn as full and broken lines, respectively. In addition to the values for the limbdarkening, attention should be directed to the almost constant gradient

$$
\frac{\mathrm{d}\left[I_{\lambda}(\mu) / I_{\lambda}(1)\right]}{\mathrm{d}(1 / \lambda)}
$$

for a fixed value of $\mu$. Evidently the Bilderberg model predicts too large values for the 


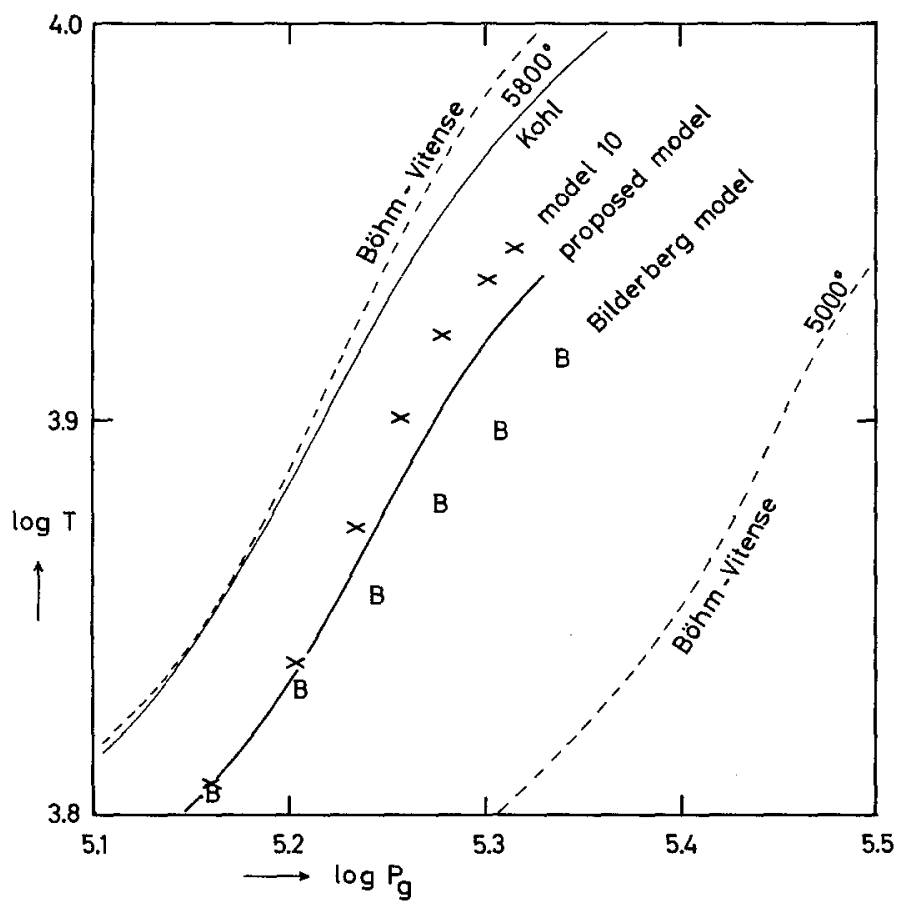

Fig. 3. Relation between temperature and pressure for the transition region to the hydrogen convection zone.

limb-darkening, and also gives a too small gradient, while the proposed model comes much closer to the observations in both respects. For the discussion of the infrared observations where the differences are becoming small, let us look at the situation for $\mu=0.6$ in more detail in Figure 4. At this limb distance the influence of the finite resolving power of the telescopes used by the different observers is not yet significant. At about $23000 \AA$ the observed points lie between the lines for the two models, but at longer wavelengths both models predict too small intensity ratios. Judging from the quite good agreement between the three different observational sets, PIfrCE et al. (1950), SAIEDY (1960), and LÉNA (1968), the observations should not be responsible for the discrepancy.

It may be mentioned, however, that the inhomogeneities could provide a key to understanding of at least part of the remaining differences. Some are hard to explain just by additional unidentified absorbers.

Let us finally compare the predicted energy distributions at the center of the solar disk with the observations. For this purpose the observations by LABS and NECKEL (1967) have been combined with the relative measurements by PIERCE (1954b) in the infrared and with the other absolute measurements by Peyturaux (1952) and by SAIEDY (1960). In order to make such a comparison meaningful in the badly blended violet and blue spectral region, the observed energies in the given intervals have been 


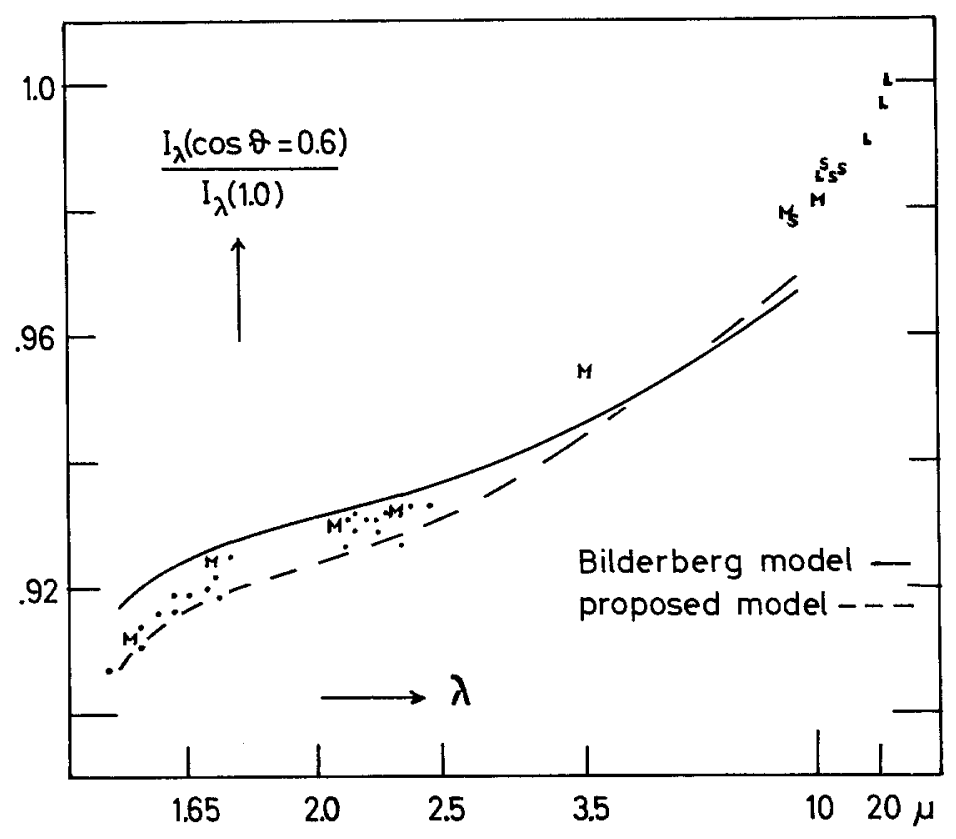

Fig. 4. Wavelength dependence of the limb-darkening in the infrared for $\cos \theta=0.6$. Observations by Pierce et al. (1950): $M$, Saiedy (1959): $S$, LéNa (1968): $L$; those by Pierce (1954) and PeyturauX (1955) are plotted as dots.

transformed to the energies of an assumed continuum. This continuum was defined by the fitting of the wings of the strongest lines as they are predicted by the model 10 . Only a few wavelength regions have been analyzed so far by employing special tracings of high resolution extended over such wavelength intervals. These tracings were obtained at the solar towers at Göttingen and at the McMath-Hulbert Observatory. The resulting logarithms of the energy of the assumed continuum at the disk center expressed in $\left[\mathrm{erg} \mathrm{cm}^{-2} \mathrm{sec}^{-1} \operatorname{ster}^{-1}\right.$ for $\left.\Delta \lambda=1 \mathrm{~cm}\right]$ are given in Table I.

TABLE I

\begin{tabular}{ccccccc}
\hline$\lambda$ & 3298.1 & 3661.0 & 3775.2 & 4020.0 & 4211.2 & 4823.3 \\
$\log E_{\lambda}$ & 14.476 & 14.551 & 14.605 & 14.667 & 14.661 & 14.616 \\
\hline
\end{tabular}

For wavelength larger than $5000 \AA$ it is sufficient to calculate the correction to the assumed continuum by using the sum over the equivalent widths of the lines in each interval. While in the wavelength region $4000 \AA<\lambda<12000 \AA$ the energy predicted by the proposed model agrees with the observations within $\frac{1}{2}$ of $1 \%$, the comparison farther into the infrared is displayed in Figure 5. The agreement can still be considered satisfactory. 


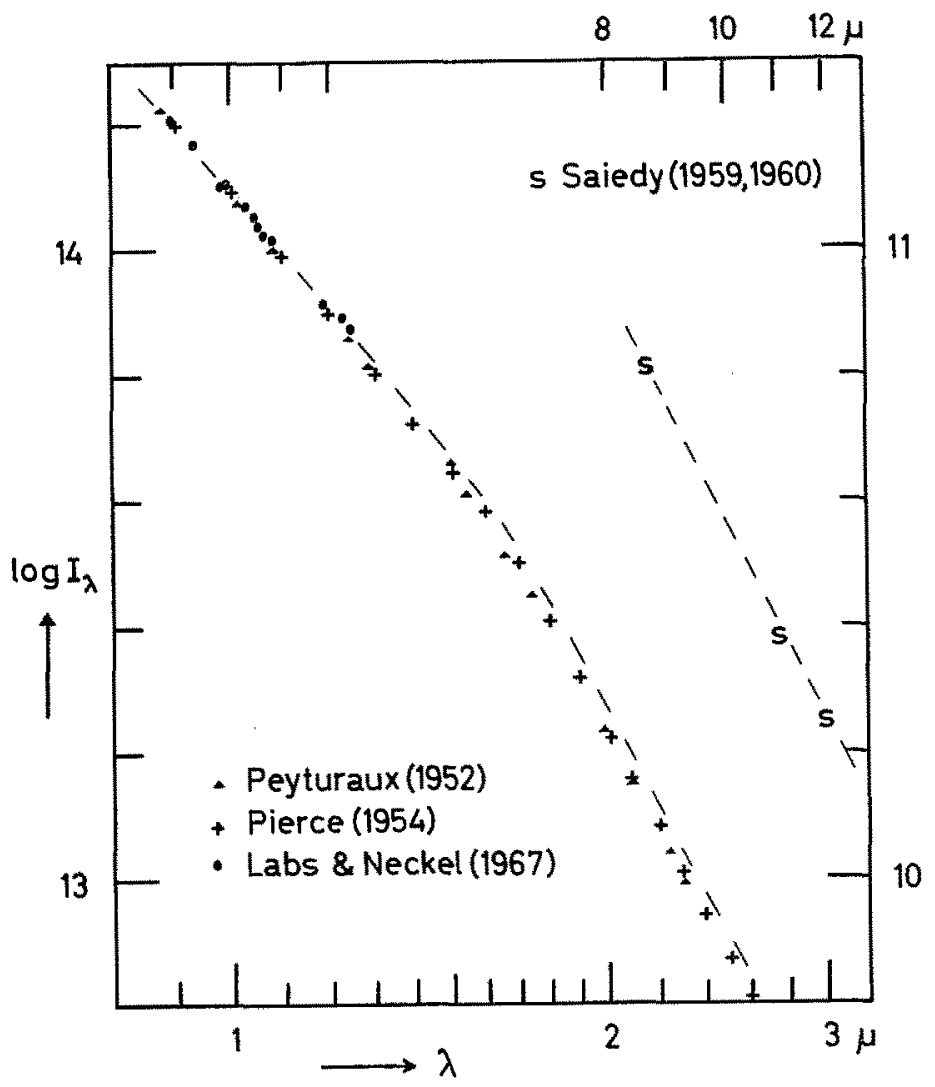

Fig. 5. Observed infrared energy distribution at the center of the solar disk compared with that predicted by the proposed model.

In order to allow the reader a quick orientation, the proposed temperature model is compared with model 10 and the Bilderberg model in Figure 6 in the form: $\Theta=5040 / \mathrm{T}$ as a function of $\log \tau_{5000}$.

\section{Pressures and Absorption Coefficients}

As has been mentioned above, pressure calculations must precede the computations of the continuous absorption coefficients. Assuming hydrostatic equilibrium we followed WEIDEMANN's (1955) suggestion and integrated the expression

$$
\sqrt{P_{\mathrm{g}}} \mathrm{d} P_{\mathrm{g}}=g m_{1} \Sigma\left(\varepsilon_{i} \mu_{i}\right) \sqrt{\left(P_{\mathrm{g}} / P_{\mathrm{e}}^{2}\right)}\left(\kappa_{5000} / P_{\mathrm{e}}\right)^{-1} \mathrm{~d} \tau_{5000},
$$

in which the quantity under the square root on the right-hand side

$$
\left(P_{\mathrm{g}} / P_{\mathrm{e}}^{2}\right)=\Sigma \varepsilon_{i}\left(1+\frac{\Phi_{i} / P_{\mathrm{e}}}{1+\Phi_{i} / P_{\mathrm{c}}}\right) / \Sigma \varepsilon_{i} \frac{\Phi_{i}}{1+\Phi_{i} / P_{\mathrm{e}}}
$$




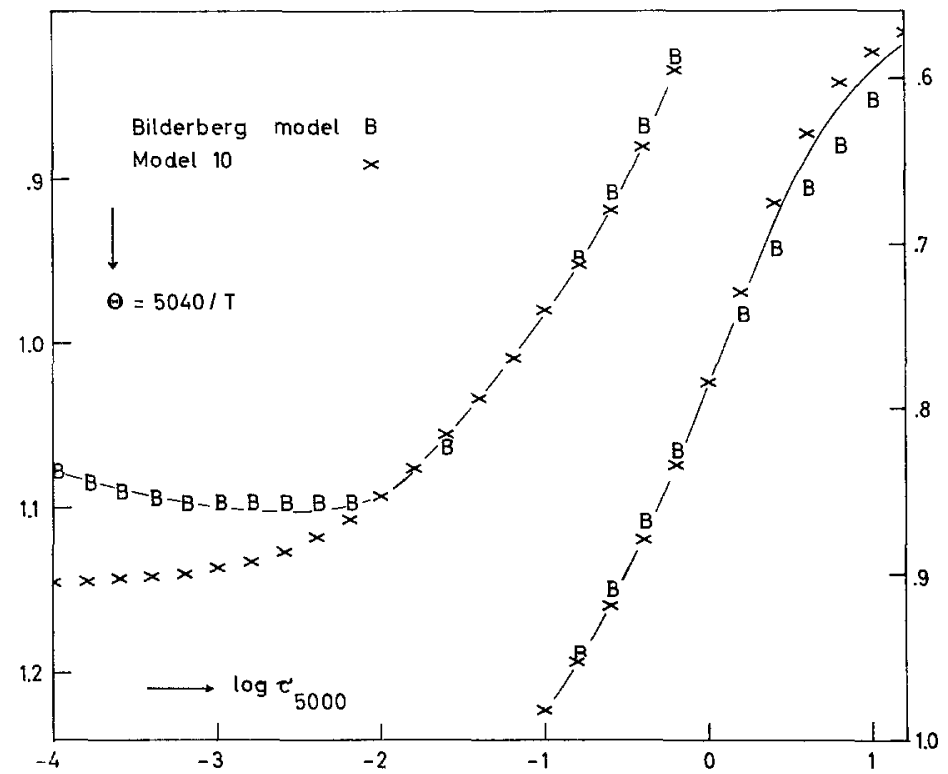

Fig. 6. Temperature stratification of the proposed model, model 10, and the Bilderberg model.

as well as $\kappa_{5000} / P_{\mathrm{e}}$ depends only slightly on the chosen value of the electron pressure, and thus enable a fast convergence of the iterative procedure.

In the above equations we have used the notation: $P_{\mathrm{g}}=$ gas pressure, $P_{\mathrm{e}}=$ electron pressure, $g=$ surface gravity, $m_{1}=$ mass of unit atomic weight, $\varepsilon_{i}=$ abundance of an element or group of elements with respect to hydrogen, $\mu_{i}=$ atomic weight of an element or group of elements, $\kappa_{5000}=$ absorption coefficient per hydrogen particle, $\tau_{5000}=$ optical depth at the wavelength $5000 \AA, \Phi_{i}=\left(n_{1} / n_{0}\right) P_{e}=$ the Saha term for the ratio of ions to atoms, multiplied by $P_{\mathrm{e}}$.

For the computations of the sums in Equations (1) and (2) the following elements were treated together in groups:

$$
\begin{aligned}
& (\mathrm{H}, \mathrm{N}, \mathrm{O}) ;(\mathrm{C}, \mathrm{S}, \mathrm{P}) ; \mathrm{Si} ;(\mathrm{Fe}, \mathrm{Cu}, \mathrm{Co}) ; \mathrm{Mg} ; \\
& (\mathrm{Ni}, \mathrm{Mn}) ;(\mathrm{Cr}, \mathrm{Ti}, \mathrm{V}) ; \mathrm{Ca} ; \mathrm{Na} ; \mathrm{K} .
\end{aligned}
$$

The integrations of Equation (1) as well as those of the optical depths have been calculated on $\log \tau_{5000}$-scale with the help of the Gauss-Encke quadrature formula (ExsTe, 1955, Eq. 37). For the starting integrals an exponential approximation was used for the integrands (ELsTe, 1957, Eq. A3b).

The data for the computation of the absorption coefficients were taken from the following sources:

$\mathrm{H}^{-}$Ion:

Bound-Free

Geltman (1962), Doughty et al. (1966)

Free-Free

for $\lambda>12000 \AA \quad$ DOUGHTY and FraSER (1966)

for $\lambda \leqslant 12000 \AA \quad$ JoHN (1964) 
H Neutral Atom:

Three nearest Bound-Free transitions and an integral over the remaining levels, as well as Free-Free transitions according to UNSöLD (1955) with Bound-Free Gaunt Factors
for $n \leqslant 3 \quad$ GINGERICH (1964)
for $n>3 \quad$ MENZEL and PEKERIs (1935)

Free-Free Gaunt Factors: KARZAS and LATTER (1961) approximated for $\chi_{\lambda} \Theta \geqslant 2.0$ by $g_{F F}-1=\Theta^{-1 / 4} 0.107$ for $\chi_{\lambda} \Theta<2.0$ by $g_{F F}-1=\Theta^{-1 / 4}\left[0.082+0.0397\left(\chi_{\lambda} \Theta\right)^{-2 / 3}\right]$

$\mathrm{H}_{2}^{+}$Molecules: Bates (1952), BogGess (1959)

Rayleigh Scattering: Dalgarno and Williams (1962), Gingerich (1964)

Metals: These are treated in hydrogenic approximation with screening factors adjusted in such a way that the resulting cross sections agree with laboratory measurements or theoretical values (employing the quantum defect method) whenever known (summarized by BODE, 1965).

TABLE II

Proposed Solar Model

\begin{tabular}{|c|c|c|c|c|}
\hline $\log \tau_{0}$ & $\Theta$ & $\log P_{\mathrm{e}}$ & $\log P_{\mathrm{g}}$ & $\log \kappa / P_{\mathrm{e}}$ \\
\hline-4.0 & 1.077 & -1.113 & 3.040 & -24.934 \\
\hline-3.8 & 1.084 & -.995 & 3.198 & -24.938 \\
\hline-3.6 & 1.089 & -.910 & 3.310 & -24.938 \\
\hline-3.4 & 1.094 & -.823 & 3.423 & -24.937 \\
\hline-3.2 & 1.097 & -.731 & 3.536 & -24.938 \\
\hline-3.0 & 1.099 & -.639 & 3.648 & -24.941 \\
\hline-2.8 & 1.102 & -.550 & 3.759 & -24.940 \\
\hline-2.6 & 1.102 & -.457 & 3.870 & -24.945 \\
\hline-2.4 & 1.102 & -.365 & 3.982 & -24.948 \\
\hline-2.2 & 1.099 & -.269 & 4.093 & -24.957 \\
\hline-2.0 & 1.092 & -.166 & 4.205 & -24.971 \\
\hline-1.8 & 1.076 & -.046 & 4.316 & -25.001 \\
\hline-1.6 & 1.056 & .081 & 4.427 & -25.037 \\
\hline-1.4 & 1.034 & .213 & 4.537 & -25.077 \\
\hline-1.2 & 1.009 & .355 & 4.647 & -25.122 \\
\hline-1.0 & .982 & .506 & 4.754 & -25.171 \\
\hline-.8 & .952 & .675 & 4.858 & -25.225 \\
\hline-.6 & .918 & .876 & 4.956 & -25.286 \\
\hline-.4 & .879 & 1.123 & 5.043 & -25.357 \\
\hline-.2 & .834 & 1.432 & 5.115 & -25.441 \\
\hline .0 & .784 & 1.796 & 5.171 & -25.538 \\
\hline .2 & .733 & 2.181 & 5.213 & -25.638 \\
\hline .4 & .686 & 2.543 & 5.245 & -25.730 \\
\hline .6 & .646 & 2.856 & 5.272 & -25.804 \\
\hline .8 & .616 & 3.094 & 5.296 & -25.853 \\
\hline 1.0 & .595 & 3.266 & 5.320 & -25.884 \\
\hline 1.2 & .582 & 3.372 & 5.336 & -25.901 \\
\hline
\end{tabular}




\section{Proposed Model}

The present model is given in steps of $\Delta \log \tau_{5000}=0.2$ for the range $-4.0 \leqslant \log \tau_{5000} \leqslant$ +1.2 . For the higher layers, $\log \tau_{5000}<-4.0$, the Bilderberg Continuum Atmosphere should be followed. Subsequent columns in Table II give the logarithm of the optical depth at $5000 \AA, \Theta=5040 / \mathrm{T}$, the logarithms of both the electron pressure, and the gas pressure in $\left[\mathrm{dyn} / \mathrm{cm}^{-2}\right]$, the logarithm of the continuous absorption coefficient at $5000 \AA$ per unit electron pressure per hydrogen particle.

\section{Acknowledgement}

The author wishes to express his gratitude to the late Professor Dr. P. ten Bruggencate, Director of the Sternwarte Göttingen, for his supporting interest during the early stage of the development of a semi-empirical solar model, as well as to the 'Aerodynamische Versuchsanstalt', the 'Max-Planck-Gesellschaft', and the University at Göttingen for granting the extensive use of the IBM-650 computer. I also wish to thank Professor Dr. O.C. Mohler for his continued interest and to Dr. R.C.F. Bartels, Director of The University of Michigan Computing Center, for permission to use the IBM-7090 computer.

\section{References}

A. CONCERNING LIMB-DARKENING OBSERVATIONS

Aвbot, C. G., Aldrich, L. B., and Fowle, F. E.: 1913, Ann. Smithson. Astrophys. Obs. 3.

Abbot, C. G., Aldrich, L. B., and Fowle, F. E.: 1922, Ann. Smithson. Astrophys. Obs. 4.

Canavaggta, R. and Chalonge, D.: 1946, 'Recherches sur le spectre continu du soleil, II: Nouvelles données d'observation', Ann. Astrophys. 9, 143.

David, K. H. and Elste, G.: 1962, 'Der Einfluss von Streulicht auf die Photometrie der Sonnenoberfläche', $Z$. Astrophys. 54, 12.*

Krat, T. W.: 1948, Poulkowo Publ. 17, no. 137.

LÉNA, P. J.: 1968, 'Observations of the Center-to-limb Variation of the Solar Brightness in the Far Infrared $(10$ to $25 \mu)$ ', Solar Phys. 3, 28.

Mitchell, Jr., W. E.: 1959, 'The Center-limb Variation of the Intensities of Selected Solar Lines', Astrophys. J. 129, 93**

Moll, W. J. H., Burger, H. C., and VAN Der BILT, J.: 1925, 'The Distribution of the Energy over the Sun's Disk', Bull. Astron. Inst. Neth. 3, 83.

Peyturaux, R.: 1952, 'Contribution a l'étude du fond continu du spectre solaire dans le proche infrarouge', Ann. Astrophys. 15, 302.

Peyturaux, R.: 1955, 'Étude du fond continu du spectre solaire, IV: L'assombrissement centre-bord du soleil entre 3190 et $23130 \AA$ ', Ann. Astrophys. 18, 34.

Pierce, A. K.: 1954a, 'Solar Limb-Darkening in the Region $\lambda \lambda$ 7793-24388', Astrophys. J. 120, 221.*

Pierce, A. K. and Waddell, J. H.: 1961, 'Analysis of Limb-Darkening Observations', Mem. Roy. Astron. Soc. 68, 89.*

Pierce, A. K., McMath, R. R., Goldberg, L., and Mohler, O.: 1950, 'Observations of Solar LimbDarkening between 0.5 and $10.2 \mu$, Astrophys. J. 112, 289.

RAUDENBUSCH, H.: 1938, 'Messùngen der Intensitätsverteilung auf der Sonnenscheibe in verschiedenen Wellenlängen', Astr. Nachr. 266, 301.

* These investigations are based on the original observations by PIERCE (1954a). 
SAIEDY, F.: 1960, 'Solar Intensity and Limb-Darkening between 8.6 and $13 \mu$ ', Monthly Notices Roy. Astron. Soc. 121, 483.

SCHMIDT, Th.: 1961, 'Photometrie der ultravioletten Kupferresonanzlinien bei 3248 und $3274 \AA$ auf der Sonne', Z. Astrophys. 53, 273.

B. GENERAL REFERENCES

Bates, D. R.: 1952, 'Absorption of Radiation by an Atmosphere of $\mathbf{H}, \mathbf{H}^{+}$and $\mathbf{H}_{2}{ }^{+}$-Semiclassical Treatment', Monthly Notices Roy. Astron. Soc. 112, 40.

Bode, G.: 1965, Die kontinuierliche Absorption von Sternatmosphären in Abhängigkeit von Druck, Temperatur und Elementhäufigkeiten. Institut für Theoretische Physik und Sternwarte der Univ. Kiel.

BoGGESS, III, A.: 1959, 'The Emission of $\mathrm{H}_{2}{ }^{+}$, Astrophys. J. 129, 432.

BÖHM-VITENSE, E.: 1958, 'Über die Wasserstoffkonvektionszone in Sternen verschiedener Effektivtemperaturen und Leuchtkräfte', Z. Astrophys. 46, 108.

Dalgarno, A. and Williams, D. A.: 1962, 'Rayleigh Scattering by Molecular Hydrogen', Astrophys. $J$. 136, 690.

David, K. H.: 1961, 'Die Mitte-Rand-Variation der Balmerlinien $\mathrm{H} \alpha-\mathrm{H} \delta$ auf der Sonnenscheibe', Z. Astrophys. 53, 37.

Doughty, N. A. and Fraser, P. A.: 1966, 'The Free-Free Absorption Coefficient of the Negative Hydrogen Ion', Monthly Notices Roy. Astron. Soc. 132, 267.

Doughty, N. A., Fraser, P. A., and McEachran, R. P.: 1966, 'The Bound-Free Absorption Coefficient of the Negative Hydrogen Ion', Monthly Notices Roy. Astron. Soc. 132, 255.

ELSTE, G.: 1955, 'Die Mitte-Rand-Variation schwacher bis mittelstarker Fraunhoferlinien auf der Sonnenscheibe', Z. Astrophys. 37, 184.

ELSTE, G.: 1957, 'Nomographic Method for Integrating a Function given on a Logarithmic Scale', Astrophys. J. Suppl. Ser, 3, 31.

Elste, G.: 1960, 'Ein neues Photosphärenmodell, abgeleitet aus Randverdunklungsmessungen unter Berücksichtigung der Wellenlängenabhängigkeit der kontinuierlichen Absorption,' Physikalische Verhandlungen 11, Nr. 11, p. 8; Mitt. astr. Ges. 14.

ELSTE, G.: 1967, 'The Distinction between Micro- and Macroturbulence in the Solar Photosphere using Line Profiles', Astrophys. J. 148, 857.

Geltman, S.: 1962, 'The Bound-Free Absorption Coefficient of the Hydrogen Negative Ion,' Astrophys. J. 136, 935.

GINGERICH, O.: 1964, Review of opacity calculations, First Harvard-Smithsonian Conference on Stellar Atm., Cambridge, Mass., 1964, in Smithson. Inst. Astrophys. Obs., spec. Rep., no. 167, p. 17.

Goldberg, L. and Pierce, A. K.: 1959, 'The Photosphere of the Sun', in Handbuch der Physik, LII: Das Sonnensystem (Ed. by S. Flügge). Springer-Verlag, Berlin-Göttingen-Heidelberg.

Goldberg, L., Müller, E. A., and Aller, L. H.: 1960, 'The Abundances of the Elements in the Solar Atmosphere', Astrophys. J. Suppl. Ser. 5, 1.

JoHN, T. L.: 1964, 'The Free-Free Transitions of the Negative Hydrogen Ion in the Exchange Approximation,' Monthly Notices Roy. Astron. Soc. 128, 93.

Karzas, W. J. and LatTer, R.: 1961, 'Electron Radiative Transitions in a Coulomb Field', Astrophys. J. Suppl. Ser. 6, 167.

KoHL, K.: 1967, 'Das Eindringen von Strömungen in die stabile Schicht unterhalb der solaren Konvektionszone', $Z$. Astrophys. 64, 472.

LABS, D.: 1957, 'Die Intensität des kontinuierlichen Spektrums der Sonnenmitte im Wellenlängenbereich $3300 \leqslant \lambda \leqslant 6900 \AA ', Z$. Astrophys. 44, 37.

Labs, D. and NeCKel, H.: 1962, 'Die absolute Strahlungsintensität der Sonnenmitte im Spektralbereich $4010 \leqslant \lambda \leqslant 6569 \AA^{\prime}, Z$. Astrophys. 55, 269.

LABS, D. and NeCKel, H.: 1963, 'Die absolute Strahlungsintensität der Sonnenmitte im Spektralbereich $6389 \leqslant \lambda \leqslant 12480 \AA$ ', $Z$. Astrophys. 57, 283.

LABS, D. and NECKEL, H.: 1967, 'Die absolute Strahlungsintensität der Mitte der Sonnenscheibe im Spektralbereich $3288 \leqslant \lambda \leqslant 12480 \AA$ ', $Z$. Astrophys. 65, 133.

MATtig, W. and Schröter, E. H.: 1961, 'Die Mitte-Rand-Variation des Kontinuums für $\bar{\lambda}=5893 \AA$ und der Flügel der Na D-Linien im Sonnenspektrum', Z. Astrophys. 52, 195.

Menzed, H. D. and Pekeris, C. L.: 1935, 'Absorption Coefficients and Hydrogen Line Intensities', Monthly Notices Roy. Astron. Soc. 96, 77. 
Mugglestone, D.: 1964, Colloquium at The University of Michigan.

Pierce, A. K.: 1954b, 'Relative Solar Energy Distribution in the Spectral Region 10000-25000 ^’, Astrophys. J. 119, 312.

SAIEDY, F. and Goody, R. M.: 1959, 'The Solar Emission Intensity at $11 \mu$ ', Monthly Notices Roy. Astron. Soc. 119, 213.

UNsöLD, A.: 1955, Physik der Sternatmosphären. 2nd ed., Springer-Verlag, Berlin-Göttingen-Heidelberg.

VARdya, M. S.: 1964, ‘Atmospheric Rosseland Mean Opacities', Astrophys. J. Suppl. Ser. 8, 277.

WeIDEmann, V.: 1955, 'Metallhäufigkeiten, Druckschichtung und Stossdämpfung in der Sonnenatmosphäre', Z. Astrophys. 36, 101.

Withbroe, J. L.: 1967, 'An Analysis of CH in the Solar Atmosphere', Astrophys. J. 147, 1117.

Withbroe, J. L.: 1968, ‘The Center-Limb Behavior of Solar Molecular Lines', Solar Phys. 3, 146. 